\title{
Evaluating the Effectiveness of a Concept-based Computer Tutorial for OPAC Users
}

\author{
Joan M. Cherry, Weijing Yuan, \\ and Marshall Clinton
}

In an experiment to evaluate the effectiveness of a concept-based computer tutorial for training OPAC users, the authors found that University of Toronto students who viewed the tutorial performed significantly better on search tasks than those who received no instruction. This paper reports the results of a second experiment to investigate the effectiveness of the computer tutorial. Fifteen students viewed the computer tutorial. Another fifteen students served as a control group and did not receive any instruction. The results showed no significant differences in performance between the students who viewed the computer tutorial and those who did not receive any instruction. We discuss the differences between the results of the two experiments in terms of the characteristics of the participants and the characteristics of the OPACs. We also relate our findings to the findings of other studies on concept-based instruction and offer suggestions for future research.

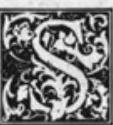

everal authors have recently advocated a move toward concept-based instruction and away from procedure-based instruction in bibliographic instruction. The basic characteristics of each type of instruction are shown in table 1.

In the context of online public access catalogs (OPACs), concept-based instruction emphasizes the general organizing and searching principles in OPACs rather than specific procedures/com- mands/steps for doing searches on a particular OPAC. Katherine Branch, Joan K. Lippincott, and Linda Brew MacDonald et al. have discussed the concepts that might be included in this type of instruction for OPAC users. ${ }^{1,2,3}$ These include:

- Principles of database organization: what a database is; the structure of a bibliographic record; searchable fields; indexing; keywords; descriptors; controlled vocabulary; freetext searching; Boolean logic.

Joan M. Cherry is Associate Professor in the Faculty of Library and Information Science, Weijing Yuan is a doctoral candidate at the Faculty of Library and Information Science, and Marshall Clinton is Director of Information Technology Services at the University of Toronto Library, Toronto, Ontario, M5S, 1A1, Canada. The development of the instructional software was supported by Apple Canada and the Research Board of the University of Toronto. The experiments to test the effectiveness of the software as an educational vehicle were supported by a grant from the Council on Library Resources, Washington, D.C. The statements made and the views expressed in this paper are the responsibility of the authors. The following individuals worked on the development of the software: Don Gibson, John Bradley, Geoffrey Rockwell, Computing Services; Sophia Kaszuba, Scienceand Medicine Library; James Turner, Faculty of Library and Information Science. The authors thank Lari Langford, Head, Information Centre, Sigmund Samuel Library for her help in recruiting participants for this study. 
TABLE 1

CHARACTERISTICS OF CONCEPT-BASED INSTRUCTION AND PROCEDURE-BASED INSTRUCTION

\begin{tabular}{|c|c|}
\hline Concept-based & Procedure-based \\
\hline * Presents a conceptual model of the system. & $\begin{array}{l}\text { Presents procedures for doing tasks with the } \\
\text { system at hand. }\end{array}$ \\
\hline $\begin{array}{l}\text { Focuses on how the system (and others of } \\
\text { its type) works. }\end{array}$ & $\begin{array}{l}\text { - Focuses on the mechanics of operating the } \\
\text { system at hand. }\end{array}$ \\
\hline * Focuses on system-independent skills. & - Focuses on system-dependent skills. \\
\hline
\end{tabular}

- Problem analysis: division of a topic into components to develop a search strategy.

- Evaluation of search output: precision, recall; limiting or broadening search.

These concepts are universal and apply to all OPAC systems.

\section{RESEARCH ON CONCEPT-BASED/ MODEL-BASED INSTRUCTION}

In a study conducted by Frank G. Halasz and Thomas P. Moran, four participants were trained to use an electronic calculator with a conceptual model of the systems while three users were not provided with the model-based training. ${ }^{4}$ The participants performed three types of tasks: routine tasks, invention tasks, and combination tasks. On the routine tasks, the no-model users were 40 percent faster than the model participants. On the invention tasks, the model users performed considerably better than the no-model users. The latter used commands more efficiently and required fewer attempts to arrive at solutions. On the combination tasks the no-model users were slightly faster.

Christine L. Borgman trained thirtytwo undergraduate students to use an online catalog. ${ }^{5}$ Half received modelbased training; half received procedurebased training. The students performed five simple tasks and five complex tasks. On the simple tasks there was no significant difference in performance between those who received the model-based and procedure-based training. On the complex tasks those who received the model-based training performed significantly better $(p=.08)$. Similarly, there were no significant differences in usage patterns, as indicated in the transaction monitoring data, between the groups on the simple tasks. There were, however, significant differences between the two groups on the complex tasks. Borgman commented that the "results were not as strong as we had hoped." She noted that a less sophisticated sample might have benefited more from the conceptual models provided. ${ }^{6}$

Piraye Bayman and Richard E. Mayer conducted a study in which novices learned BASIC computer programming.? Some received conceptual instruction; others received standard instruction. The study included high ability subjects (as measured by the Scholastic Aptitude Test (SAT), and low ability subjects. Results of a programming test indicated that the conceptual instruction enhanced problem-solving performance for low ability subjects but not for high ability subjects.

\section{POTENTIAL BENEFITS OF CONCEPT-BASED TRAINING}

Theresa L. Wesley provides a useful summary of the benefits of conceptbased instruction which have been suggested by previous research. ${ }^{8}$ The benefits of concept-based instruction fall into three categories: user performance, learning transfer, and judgment.

\section{Improved User Performance}

Users will:

- perform better on advanced or nonroutine tasks;

- have less trouble extricating themselves from errors; 
- be better able to make inferences and predictions;

- be able to better structure searches and interpreting results.

\section{Learning Transfer}

Users will:

- be able to apply their knowledge to new situations;

- be better able to move from one vendor's system to another, or to deal with a new release of an existing system;

- be better able to use other related systems (e.g., users who receive conceptbased OPAC training will be better able to use end-user online systems, CD-ROM products, etc.).

\section{Judgment}

- users will understand the limitations of the system.

Elizabeth Frick and Mary M. Huston discuss the merits of concept-based instruction.9,10 Both refer to Christine Borgman's comment that while mastery of the mechanical aspects of searching may insure some results from the system, it is only when the conceptual aspects are understood that users can exploit the system fully.

Unfortunately, much of the OPAC instruction provided by libraries has not been concept-based. Frick refers to Nowakowski's mid-1980s survey of seventy-two Canadian academic and public libraries using OPACs." Nowakowski concluded that the use of different systems, each with its own idiosyncrasies, had resulted in libraries concentrating on teaching the user how to use their system rather than giving them skills which could translate to other systems. Giving users skills that can transfer to other systems seems even more important today since gateways such as the Internet have increased access to systems.

\section{A CONCEPT-BASED COMPUTER TUTORIAL FOR OPAC USERS}

The authors have developed a computer tutorial to deliver concept-based training in the use of OPACs. The tutorial runs on stand-alone microcomputers in the library. The software was developed by a team that included two of the authors of this paper, staff from the University of Toronto Computing Services, a computer graphics consultant, a professional librarian, and several graduate students in the Faculty of Library and Information Science. The software runs on a Macintosh SE and was produced with Hypercard.

The computer tutorial aims at the naive user. The system consists of modules for various aspects of OPAC searching. Each module is intended for use in linear fashion. However, users may view the modules in any sequence and may exit a module at any point.

\section{Giving users skills which can transfer to other systems seems even more important today since gateways such as the Internet have increased access to systems.}

The tutorial incorporates graphics, sound, animation, as well as digitized video clips and speech. Throughout the system these are usually used to provide additional information content, or to reinforce concepts being explained in the tutorial.

The tutorial presents concepts in such a way that they apply to any online cata$\log$. The general organizing and searching principles in online catalogs are the focus of the content. Analogies used to convey the intellectual content include everyday items such as the telephone book and the traditional card catalog. The instructional design of the software is described in detail in an earlier paper. ${ }^{12}$ The design of the interface of the software is also discussed in another paper. ${ }^{13}$

In an earlier experiment to evaluate the effectiveness of the concept-based computer tutorial we found that students who viewed the computer tutorial performed significantly better on search tasks than those who received no instruction, and performed as well as students who received the standard classroom lecture provided by the University of Toronto Library. ${ }^{14}$ The search tasks were performed on the Utlas T/Series-50 
OPAC at the University of Toronto. These results were encouraging because the ability to deliver instruction effectively through computer tutorials offers potential benefits to both libraries and their users. For libraries, it offers the benefit of reduced staff time for classroom instruction; for users it offers an opportunity to learn independently, a learning style reported by many OPAC users. ${ }^{15}$

Concept-based computer tutorials offer two additional advantages for library users and libraries: the concepts learned from the tutorials should be transferable; for example, if the tutorial explains OPAC concepts, users should be more proficient with any OPAC. Once developed, the computer tutorials could be used in a variety of libraries, thus providing an opportunity for a library to benefit from development work undertaken at another institution. The experiment reported in this paper was designed to evaluate the effectiveness of our concept-based computer tutorial for training students to use a different OPAC.

\section{METHODOLOGY}

\section{Design}

Thirty students participated in the experiment which consisted of a pretest and a task session, conducted with one participant at a time. In the pretest, participants completed a background questionnaire and a library skills assessment. In the task sessions, participants were randomly assigned to one of two conditions: to view the computer tutorial, or to receive no instruction. All participants used the Data Research Associates (DRA) OPAC at Tufts University to answer nine questions. We selected this OPAC because the University of Toronto Library had recently contracted to install the DRA system and we could access the OPAC at Tufts University through Telnet. Participants in the No Instruction condition were given an opportunity to use the tutorial at the end of the session. The study was conducted in January and February of 1992 in a research laboratory at the Faculty of Library and Information Science, University of Toronto.

\section{Participants}

One-third of the participants were undergraduate students. Seventeen percent were graduate students. They were recruited through advertisements on University of Toronto campus. Most of the others ( 43 percent) were students enrolled in the preuniversity program at the university. Their curriculum includes a component on use of library resources and the development of bibliographic skills. The head of the Information Centre at the Sigmund Samuel (undergraduate) Library recruited these participants while they were on a required tour of the library.

Participation in the experiment was voluntary. Students received $\$ 10$ for their participation. As with all studies that use volunteers, the participants may differ in some ways from those who did not volunteer. For instance, the participants may have been more motivated than those who did not volunteer.

\section{The Pretest}

The pretest included two parts: a background questionnaire and a library skills assessment. (A copy of the pretest is available from the authors.) Participants were given twenty minutes to read a one-page description of the study and to complete the pretest.

\section{The Task Sessions}

The task sessions were held immediately after the pretest. The participants were randomly assigned to the No Instruction condition or the Computer Tutorial condition.

Computer Tutorial Condition. The students in the Computer Tutorial condition were given twenty minutes to view the tutorial. The tutorial included only conceptual information. Since time for viewing the tutorial was limited, participants were told that the Author Searching, Title Searching, and Subject Searching modules of the tutorial were most relevant for the experiment, and the observer suggested that they focus on these sections.

We limited the tutorial viewing time to twenty minutes so that we could com- 
TABLE 2

DISTRIBUTION OF PARTICIPANTS BY PRIOR CATALOGUE EXPERIENCE

\begin{tabular}{lcccccc}
\hline & \multicolumn{7}{c}{$\begin{array}{c}\text { \% } \\
\text { \% All } \\
N=30\end{array}$} & $\begin{array}{c}\text { Computer } \\
\text { Tutorial } \\
N=15\end{array}$ & $\begin{array}{c}\text { \% No } \\
\text { Instruction } \\
N=15\end{array}$ & chi-sq & df & $p$ \\
\hline $\begin{array}{c}\text { Used University of Toronto } \\
\text { OPAC before }(N=30)\end{array}$ & 83.3 & 86.7 & 80.0 & 0.240 & 1 & .624 \\
$\begin{array}{c}\text { Used other OPAC }(N=30) \\
\begin{array}{c}\text { Received OPAC instruction } \\
\quad(N=30)\end{array}\end{array}$ & 63.3 & 66.7 & 60.0 & 0.144 & 1 & .705 \\
$\begin{array}{c}\text { Received card catalog } \\
\text { instruction }(N=30)\end{array}$ & 40.0 & 33.3 & 46.7 & 0.556 & 1 & .456 \\
\hline
\end{tabular}

Percentage represents the proportion of "yes" responses to the items. Missing values were excluded.

pare the results of this experiment with those from the first experiment, where participants in the Classroom Lecture group received a twenty-minute lecture by a librarian, and participants in the Computer Tutorial group spent twenty minutes viewing the tutorial. Each student in the Computer Tutorial group was tested immediately following the twenty-minute instruction period.

No Instruction Condition. Students who were assigned to the No Instruction condition did not receive any instruction prior to doing the searches in the task session. They were given an opportunity to view the computer tutorial after completing the task session.

Search Tasks. The participants worked on nine search tasks that also were used in the first experiment. (The list of search tasks is available from the authors.) These tasks were modeled on search tasks used in an earlier study by Mary Ellen Larson and Dace Freivalds. ${ }^{16}$ Participants were given twenty minutes to do the search tasks. The search tasks were performed on the Tufts University OPAC, a Data Research Associates (DRA) system.

\footnotetext{
RESULTS

\section{Background of Participants}

The undergraduates, graduate students, and preuniversity program students were evenly distributed across the Computer Tutorial and No Instruction groups. We asked a number of questions about the participants' prior experience
}

with library catalogs and instruction in their use. These data are shown in table 2. As can be seen from table 2, over 80 percent of the participants had used the University of Toronto OPAC before, over 60 percent had used another OPAC, and 40 percent had received OPAC instruction. Table 2 shows that there were no significant differences between the two groups on these variables; thus the groups appeared to be comparable.

Participants were asked to indicate how many times they had used the University of Toronto OPAC: Never, 1-10 times, 11-20 times, 21-30 times, 31-40 times, or More than 40. Table 3 summarizes the participants' responses to this question. As can be seen from table 3, most of those who had

TABLE 3

PREVIOUS USAGE OF UNIVERSITY OF TORONTO OPAC (UTLAS T/SERIES-50)

\begin{tabular}{cccc}
\hline & $\begin{array}{c}\% \\
\% \text { All } \\
(N=30\end{array}$ & $\begin{array}{c}\text { Computer } \\
\text { Tutorial } \\
(N=15)\end{array}$ & $\begin{array}{c}\text { \% No } \\
\text { Instruction } \\
(N=15)\end{array}$ \\
\hline Never & 16.7 & 13.3 & 20.0 \\
$1-10$ times & 56.7 & 60.0 & 53.3 \\
$11-20$ times & 6.7 & - & 13.3 \\
$21-30$ times & 3.3 & - & 6.7 \\
$31-40$ times & 10.0 & 20.0 & - \\
$\begin{array}{c}\text { More than } \\
40 \text { times }\end{array}$ & 6.7 & 6.7 & 6.7 \\
\hline
\end{tabular}


TABLE 4

COMPUTER EXPERIENCE OF PARTICIPANTS

\begin{tabular}{lcccccc}
\hline & \multicolumn{7}{c}{$\begin{array}{c}\text { \% All } \\
(N=30)\end{array}$} & $\begin{array}{c}\text { Computer } \\
\text { Tutorial } \\
(N=15)\end{array}$ & $\begin{array}{c}\text { \% } \\
\text { No } \\
(N=15)\end{array}$ & chi-sq & df & $p$ \\
\hline CD-ROM databases & 30.0 & 33.3 & 26.7 & 0.159 & 1 & .690 \\
$\begin{array}{l}\text { Database management } \\
\quad \text { systems }\end{array}$ & 23.3 & 13.3 & 33.3 & 1.677 & 1 & .195 \\
Electronic spreadsheets & 30.0 & 33.3 & 26.7 & 0.159 & 1 & .690 \\
Video games & 53.3 & 46.7 & 60.0 & 0.536 & 1 & .464 \\
Word processors & 73.3 & 80.0 & 66.7 & 0.682 & 1 & .409 \\
Own a computer & 43.3 & 33.3 & 53.3 & 1.222 & 1 & .269 \\
\hline
\end{tabular}

Percentage of participants who have used each type of software.

TABLE 5 PRETEST SCORES

\begin{tabular}{lcc}
\hline $\begin{array}{l}\text { All } \\
(N=30)\end{array}$ & $\begin{array}{c}\text { Computer } \\
\text { Tutorial } \\
(N=15)\end{array}$ & $\begin{array}{c}\text { No } \\
\text { Instruction } \\
(N=15)\end{array}$ \\
\hline 28.6 & 27.3 & 29.9 \\
\hline
\end{tabular}

Mean number of questions answered correctly.

used the University of Toronto OPAC had used it ten times or fewer. The groups did not differ significantly with respect to previous usage of the University of Toronto OPAC ( chi-sq $=6.259, d f=5, p=.282$ ).

We were also interested in the types of software the participants had used. Table 4 summarizes the participants' experience with computers.There were no significant differences between the groups on any of the six variables.

\section{Library Skills Assessment}

The maximum score possible on the Library Skills Assessment was 39 . The mean score for the thirty participants was 28.6. Scores ranged from 12 to 39 , with a standard deviation of 8.34. The means for the Pretest scores are shown in table 5. A $t$-test indicated that the difference between the scores of the two groups was not significant $(t=0.828, p=0.415)$.

The questions which were most frequently answered incorrectly are shown in table 6 . The pattern is similar to that found in the first experiment. These data again suggest that students need instruction on sequencing Library of Con- gress call numbers and distinguishing between citations to books and journal articles.

\section{Performance on the Search Tasks}

The number of search tasks completed successfully was the measurement of performance. The maximum score possible was 9 . The mean score for the thirty participants was 5.2. Scores ranged from 2 to 9 , with a standard deviation of 2.46 . The mean scores of the two groups are shown in table 7. Although those who received the computer tutorial scored slightly higher (5.3 versus 5.1 ) a $t$-test indicated that the difference between the scores of the two groups was not significant $(t=0.293, p=0.772)$.

\section{As with all studies that use volunteers, the participants may differ in some ways from those who did not volunteer.}

\section{Evaluation Questionnaire}

After doing the searches in the Posttest, participants completed an evaluation questionnaire (available from the authors). It included a question which asked how confident they were that they would be able to use the OPAC in future, and a question which asked how much the instruction received (the computer tutorial) had helped them to answer the search questions in the experimental ses- 
TABLE 6

QUESTIONS THAT WERE ANSWERED INCORRECTLY MOST FREQUENTLY

\begin{tabular}{lc}
\hline Question & $\%$ \\
\hline A book with this call number (L8601.B89) would be placed on the shelf: (\#21) & 46.4 \\
$\begin{array}{l}\text { A summary of the contents of an article, book, or other material: (\#5) } \\
\text { A book with this call number (L1010.D12) would be placed on the shelf: (\#20) }\end{array}$ & 43.3 \\
$\begin{array}{l}\text { In order to determine how thoroughly a topic is covered in a book, look the topic } \\
\text { up in the: (\#29) }\end{array}$ & 39.3 \\
$\begin{array}{l}\text { Which of the entry numbers are for magazine or journal articles about Davies? } \\
\text { (\# 22) }\end{array}$ & 36.0 \\
$\begin{array}{l}\text { The part of the book that gives the name of the author, the name of the book, the } \\
\text { publisher, and the date of publication is the: (\#24) }\end{array}$ & 35.7 \\
$\begin{array}{l}\text { Items in great demand that are available for limited loan periods in a special sec- } \\
\text { tion of the library: (\#6) }\end{array}$ & 29.6 \\
$\begin{array}{l}\text { How many articles are listed under the subject "solar energy"? (\#30) } \\
\text { Which of the following entry numbers are for books or parts of books about } \\
\text { Davies? (\#23) }\end{array}$ & 27.6 \\
\hline
\end{tabular}

$(N=30)$ Percentage represents the proportion of incorrect responses to the questions. Missing values were excluded.

sion. The data for these questions are presented in table 8. In constructing this table we excluded observations where participants did not respond to the question.

Table 8 shows the percentage of participants in each group who felt confident that they could use the OPAC to identify and locate library materials and shows the opinions of those who viewed the computer tutorial on whether the

\section{TABLE 7}

\section{POSTTEST SCORES - SEARCHES ON TUFTS UNIVERSITY OPAC (DRA)}

\begin{tabular}{lcc}
\hline $\begin{array}{l}\text { All } \\
(N=30)\end{array}$ & $\begin{array}{c}\text { Computer } \\
\text { Tutorial } \\
(N=15)\end{array}$ & $\begin{array}{c}\text { No } \\
\text { Instructions } \\
(N=15)\end{array}$ \\
\hline 5.2 & 5.3 & 5.1 \\
\hline
\end{tabular}

Mean number of questions answered correctly. instruction that they had received had helped them to answer the questions in the exercise. As we can see from table 8, in both groups, a majority of participants were confident that they could use the OPAC $($ chi-sq $=4.86, d f=4, p=.302)$. Most reported that the instruction had helped them to answer the questions in the exercise although their performance on the search tasks was not significantly better than those who had not received any instruction.

\section{Transaction Logs}

During the experimental sessions, we recorded the interaction between the participant and the OPAC, i.e., the entire search process, using the communications software. Using the transaction log data, we compared the behavior of the two groups with respect to types of searches

TABLE 8

EVALUATION OF INSTRUCTION

\begin{tabular}{cccccc}
\hline & $\%$ Strongly & $\%$ & $\%$ No & $\%$ & $\%$ Strongly \\
& Disagree & Disagree & Opinion & Agree & Agree \\
\hline
\end{tabular}

I am confident that I can use the computerized catalog to identify and locate materials in the library.

$\begin{array}{lcrrrr}\text { Computer tutorial }(N=15) & - & 20.0 & 13.3 & 46.7 & 20.0 \\ \text { No instruction } & 13.3 & 6.7 & 6.7 & 66.7 & 6.7\end{array}$

The instructions I received in the use of the computerized catalog helped me to answer the questions in this exercise.

Computer tutorial $(N=15)$

$-$

20.0

6.7

66.7

6.7 
TABLE 9

COMPARISON OF DATA FROM TRANSACTION LOGS

\begin{tabular}{lcc}
\hline & $\begin{array}{c}\text { Computer } \\
\text { Tutorial } \\
(N=15) \\
\text { Mean }\end{array}$ & $\begin{array}{c}\text { No } \\
\text { Instruction } \\
(N=14) \\
\text { Mean }\end{array}$ \\
\hline Author searches & 4.3 & 5.6 \\
Title searches & 6.2 & 4.8 \\
Subject searches & 4.3 & 3.6 \\
Keyword searches & 0.5 & 0.4 \\
Zero-hit searches & 4.9 & 4.8 \\
Records retrieved & 27.4 & 23.9 \\
Browse/navigation & 24.5 & 21.3 \\
Help requests & 0.6 & 1.1 \\
Error messages & 4.1 & 2.5 \\
\hline
\end{tabular}

performed, search results, navigation and browsing, and problems encountered, as reflected by error messages. These data are shown in table 9. The differences between the two groups on these measures were not significant.

In some of the chi-square analyses, some cell expected frequencies are less than five. Traditionally, statisticians have recommended that expected frequencies should be equal to or greater than five. However, some statisticians now believe that this is not necessary. ${ }^{17,18}$

\section{SUMMARY AND DISCUSSION}

The results of the first experiment to test the concept-based computer tutorial showed that those who viewed the tutorial performed significantly better on search tasks than those who received no instruction. However, the results of the experiment reported in this paper showed that students who received no instruction performed as well as those who received the computer tutorial.

In this section we discuss the differences between the results of the two experiments in terms of the characteristics of the OPACs and the participants. We also relate our findings to the findings of other studies on concept-based instruction.

The main difference between the two experiments was the OPAC used. In the first experiment the OPAC was the Utlas T-Series/50 system. In the second experiment the OPAC was the Data Re- search Associates (DRA) system. The participants completed more of the tasks on average in the second experiment than in the first ( 5.1 vs 3.4 ). This may indicate that the DRA OPAC is easier to learn/use than the Utlas T-Series/50 OPAC, and that instruction (at least of the type provided in the computer tutorial) is not necessary. However, it may be because of differences in the task sessions. In the first experiment, the task sessions were conducted with groups, whereas in the second experiment, the sessions were conducted with one participant at a time. The participants in the second experiment may have been more motivated to perform the tasks.

Most believed that the instruction had helped them to answer the questions in the exercise although their performance on the search tasks was not significantly better than those who had not received any instruction.

The results of the first experiment also showed that a significantly greater percentage of those who viewed the tutorial were confident that they could use the OPAC than those who received no instruction. In contrast, the results of the second experiment showed that as large a percentage of students who received no instruction were confident that they could use the OPAC. This may also be because DRA was easier for the participants to learn and use and it inspired greater confidence in them.

However, the differences in the results of the two experiments may also occur because of differences in the characteristics of the participants. There were more experienced OPAC users in the second experiment than in the first. In addition, more participants in the second experiment had used CD-ROM databases, database management systems, and electronic spreadsheets. Thus, participants overall in the second experiment had a higher level of computer literacy than those in the first experiment. This could explain why the par- 
ticipants in the second experiment completed more tasks than the participants in the first experiment. It may also account for the lack of effect of the conceptbased instruction. It would suggest that those with higher levels of computer literacy (especially with search software) may benefit less (or not at all) from concept-based instruction, such as that provided in the computer tutorial. This would be consistent with the findings of previous studies that have shown that students with "lower ability" benefit more from concept-based training. For example, in a study of computer programming, Bayman and Mayer found that students of lower ability benefited more from concept-based instruction than those of higher ability (as measured by SAT scores). ${ }^{19}$ Similarly, in discussing a study of OPAC instruction conducted at Stanford University where the results were not as strong as she had hoped, Borgman commented that a less sophisticated sample might have benefited more from the conceptual models provided. ${ }^{20}$

\section{FUTURE RESEARCH}

Future research should include studies to further investigate the relationship between user experience and the impact of concept-based instruction. For example, this experiment could be repeated using a homogeneous group of less experienced university students, or the experiment could be repeated in a public library setting or high school setting. In such studies, researchers should carefully control for experience so that they can explore the relationships between various types of computer knowledge and bibliographic skills and the impact of concept-based computer tutorials. Future studies could also compare the concept-based computer tutorial to other forms of instruction; for example, the online tutorial (UTLearn) implemented at the University of Toronto could be compared with the newly installed OPAC (Data Research Associates). In such a study the form of delivery (via computer) of the instruction would be the same, but the content of the instruction would differ in that UTLearn is not restricted to concept-based material. In any future studies we suggest that researchers include more difficult tasks to enable them to detect any benefits that might relate only to performance on complex tasks.

\section{REFERENCES AND NOTES}

1. Katherine Branch, "Developing a Conceptual Framework for Teaching End User Searching," Medical Reference Services Quarterly 5 (Spring 1986): 71-76.

2. Joan K. Lippincott, "End-User Instruction: Emphasis on Concepts," in Conceptual Frameworks for Bibliographic Education: Theory into Practice, ed. Mary Reichel and Mary Ann Ramey (Littleton, Colo.: Libraries Unlimited, 1987), 183-91.

3. Linda Brew MacDonald, Mara R. Saule, Margaret W. Gordon, and Craig A. Robertson, Teaching Technology in Libraries: A Practical Guide (Boston, Mass.: G.K. Hall, 1991), 125-26.

4. Frank G. Halasz and Thomas P. Moran, "Mental Models and Problem Solving in Using a Calculator," in CHI '83: Human Factors in Computing Systems, Boston, Dec. 12-15, 1983. Proceedings (New York: Association for Computing Machinery, 1984), 212-16.

5. Christine L. Borgman, "The User's Mental Model of an Information Retrieval System: An Experiment on a Prototype Online Catalog," International Journal of Man-Machine Studies 24 (1986): 47-64.

6. Ibid.

7. Piraye Bayman and Richard E. Mayer, "Using Conceptual Models to Teach BASIC Computer Programming," Journal of Educational Psychology 80 (1988): 291-98.

8. Theresa L. Wesley, "Instructional Program Design: A Re-examination in Light of New OPAC Demands," Technicalities 11 (Mar. 1991): 9-11.

9. Elizabeth Frick, "Theories of Learning and Their Impact on OPAC Instruction," Research Strategies 7 (Spring 1989): 67-78.

10. Mary M. Huston, "Toward Contextual Sensitivity: Approaches to End User Instruction in the USA," Electronic Library 7 (June 1989): 164-67. 
11. Frick, "Theories of Learning and Their Impact on OPAC Instruction", 67-78.

12. Joan M. Cherry, James Turner, and Marshall Clinton, "Online Public Access Catalogues (OPACs): Design of Instructional Software for User Training," in 1990 ASIS Annual Meeting. Proceedings, 143-50.

13. Joan M. Cherry, Geoffrey M. Rockwell and James M. Turner, "Designing for Diversity: The User Interface for a Hypermedia Information System on a University Campus," Behavior and Information Technology 11 (1992): 1-12.

14. Joan M. Cherry and Marshall Clinton, "An Experimental Investigation of Two Types of Instruction for OPAC Users," Canadian Journal of Information Science 16 (Dec. 1991): 2-22.

15. Joan M. Cherry and Marshall Clinton, "A Profile of OPAC Users and Their Satisfaction with OPACs at Five Universities," Canadian Library Journal 49 (Apr. 1992): 123-33.

16. Mary Ellen Larson and Dace Freivalds, The Effect of an Instruction Program on Online Catalog Users. Final Report (Washington, D.C.: Association of Research Libraries, Office of Management Studies, Dec. 1984).

17. John T. Roscoe, Fundamental Research Statistics for the Behavioral Sciences, 2d ed. (New York: Holt, 1969).

18. Marija J. Norusis, SPSSX Introductory Statistics Guide (New York: McGraw-Hill, 1983).

19. Bayman and Mayer, "Using Conceptual Models to Teach BASIC Computer Programming," 291-98.

20. Borgman, "The User's Mental Model of an Information Retrieval System: An Experiment on a Prototype Online Catalog," 60. 